\title{
Predictors of Bleeding from Esophageal Varices: The Role of Factor VII and von Willebrand Factor (vWF)
}

\author{
Ali Abdelrahman Ghweil ${ }^{*}$, Usama Ahmed Arafa², Ashraf Khodeary ${ }^{3}$, Ahmed N. Salem³ \\ ${ }^{1}$ Tropical Medicine and Gastroenterology, South Valley University, Qena, Egypt \\ ${ }^{2}$ Internal Medicine, Sohag University, Sohag, Egypt \\ ${ }^{3}$ Clinical Pathology, Sohag University, Sohag, Egypt \\ Email: ${ }^{*}$ alimena1@yahoo.com
}

Received 14 February 2014; revised 18 March 2014; accepted 26 March 2014

Copyright (C) 2014 by authors and Scientific Research Publishing Inc.

This work is licensed under the Creative Commons Attribution International License (CC BY). http://creativecommons.org/licenses/by/4.0/

(c) (i) Open Access

\begin{abstract}
Objectives: Bleeding from gastroesophageal varices is the most serious and life-threatening complication of cirrhosis and accounts for $\mathbf{1 0 \%}$ of all cases of bleeding from the upper GI tract. It is essential to identify and treat those patients at the highest risk because each episode of variceal hemorrhage carries a 20 percent to 30 percent risk of death, and up to 70 percent of patients who do not receive treatment die within one year of the initial bleeding episode. The aim of this study is to determine the clinical predictors of bleeding esophageal varices and study the role of F VII (factor VII) and vWF (von willebrand factor) in predicting bleeding in patients with eosphogeal varices. Methods: A case control study was done on all patients with esophageal varices admitted at Sohag and Qena faculty of medicine hospitals from January 2012 to August 2013. Various clinical, laboratory and endoscopic variables were tested to determine the predictors of esophageal bleeding. Results: Among 300 patients with esophageal varices, 80 percent was due to hepatitis $C$ virus (HCV), 18 percent was due to hepatitis B virus (HBV), and 2 percent had both HCV and HBV. As an etiologic factor for their liver disease, hemoglobin was $10.12 \pm 2.26 \mathrm{~g} / \mathrm{l}$, platelet count $135.55 \pm 65.94 \times 10^{9} / \mathrm{l}$, prothrombin time $14.1 \pm 0.92$ second, albumin $2.88 \pm 0.71 \mathrm{~g} / \mathrm{dl}$, ALT $48.25 \pm$ $24.15 \mathrm{u} / \mathrm{l}$, total bilirubin $1.92 \pm 1.36 \mathrm{mg} / \mathrm{dl}$. Factor VII was $27.4 \pm 8.92$ percent and vWF was 188.33 $\pm 13.66 \mathrm{IU} / \mathrm{dl}$. Splenomegaly was reported 79.6 percent, 90.3 percent had ascites. 35 percent had grade III esophageal varices, 29 percent had four-column esophageal varices on endoscopy, 13.7 percent had concomitant gastric varices and 38.3 percent had portal hypertensive gastropathy. Platelet count, presence of red color sign, the number of columns of esophageal varices, presence of portal gastropathy on eosphagogastroduodenoscopy (EGD) showed a significant positive correlation with bleeding. There is a significant decrease of FVII and a significant increase of vWF in
\end{abstract}

\footnotetext{
*Corresponding author.
} 
bleeding group in comparison with non bleeding group. Conclusion: Thrombocytopenia, presence of encephalopathy and endoscopic findings of large varices, presence of red color sign, and portal hypertensive gastropathy were found to be predictors of esophageal variceal bleeding. Increase of vWF and decrease of FVII are laboratory predictors of esophageal variceal bleeding.

\section{Keywords}

\section{Esophageal Varices; FVII; von Willebrand Factor}

\section{Introduction}

Bleeding from gastro-oesophageal varices is the most serious and life-threatening complication of cirrhosis and accounts for $10 \%$ of all cases of bleeding from the upper GI (gastrointestinal) tract. Despite the advances in treatment of variceal bleeding, mortality remains high at around $40 \%$, being closely related to the severity of underlying liver disease as assessed by child's class and impairment of renal function [1].

Clinical factors associated with an increased risk of a first variceal hemorrhage include continued alcohol use and poor liver function. Endoscopic predictors of bleeding include endoscopic red signs on the variceal wall and large varices [2].

Thrombocytopenia, ascites and splenomegaly are useful non invasive parameters to predict bleeding from esophageal varices [3]. Factor (F)V and factor VII (FVII) levels are sensitive indicators of hepatic protein synthesis often used to assess the severity of disease [4] [5]. FVII is the first clotting factor level to fall, because of its short half-life of 6 hours. FVII deficiency develops in $75 \%$ - 85\% of patients, and levels range from $23 \%$ to $74 \%$ of normal in compensated cirrhosis [4]-[7]. FVII levels are significantly lower in decompensated cirrhosis, but $30 \%$ of normal ones are in most patients with stable disease [4] [5] [8].

The elevated levels of vWF (von Willebrand factor) in cirrhosis may be a consequence of endothelial perturbation, possibly caused by bacterial infection [5]. Another possible mechanism of elevated vWF in cirrhosis is induction of synthesis of vWF in the liver with cirrhosis itself [8] or reduced liver-mediated clearance. Although it is established that vWF antigen levels are increased in patients with cirrhosis, relatively little is known on the relation between it and the bleeding from esophageal varices [9] [10] so we aimed in this study to determine the clinical predictors of bleeding esophageal varices and study the role of FVII and vWF in predicting bleeding in patients with eosphogeal varices.

\section{Materials and Methods}

All patients with a clinical diagnosis of liver cirrhosis who underwent endoscopy at Qena and Sohag faculty of medicine hospitals from January 2012 to August 2013 were divided into 2 groups. Group A consisted of patients with a history and clinical presentation of bleeding esophageal varices and Group B were those patients with esophageal varices on endoscopy but with no history of variceal bleeding. The diagnosis of cirrhosis was based on a combination of clinical, laboratory and radiographic criteria.

Bleeding esophageal varices is defined as those patients who presented with upper gastrointestinal bleeding manifested by hematemesis, melena and/or hematochezia with endoscopic confirmation of esophageal variceal bleeding and no other bleeding lesion seen on endoscopy. Patients with a clinical diagnosis of upper gastrointestinal bleeding due to acquired coagulopathy, gastric ulcers, duodenal ulcers or gastric varices were excluded. All patients underwent complete clinical examination, abdominal sonography laboratory investigations and upper GIT endoscopy.

Forty patients from each group A and B are randomly selected and Factor VII and vWF are estimated.

\subsection{Abdominal Ultrasound Findings}

- portal vein diameter

- splenomegaly

- ascites 


\subsection{Endoscopic Data}

Esophageal varices were graded according to Japanese Research for Portal Hypertension Classification System as follows: grade (Gr) I: small esophageal varices which flatten with insufflation or minimally protrude into the esophageal lumen, Gr II: moderated sized varices with minimal obscuring of the gastroesophageal junction, Gr III: large varices showing luminal proplapse substantially obscuring the gastroesophageal junction and Gr IV: very large esophageal varices completely obscuring the gastroesophageal junction and do not flattens on insufflation. The number of variceal columns, presence of red color sign, presence of gastric varices and portal gastropathy were also recorded.

\subsection{Laboratory Investigations}

$7 \mathrm{ml}$ venous blood was obtained from all patients and divided in 3 tubes, one on EDTA for CBC, the second on Na citrate for prothrombin time and coagulation factors and the third contain no anticoagulant for the biochemical tests. The laboratory investigations were included CBC, AST, ALT, prothrombin time and concentration, albumin and bilirubin level, factor VII and vWF.

\subsection{Factor VII Assay Principle}

Factor VII was measured using the Sysmex CA-1500 System, a fully-automated blood coagulation analyzer. Coagulation factor VII deficient plasma is a human plasma-based reagent for the detection of hereditary or acquired deficiencies of factor VII. It is manufactured by immunoabsorption and contains a residual factor concentration of $<1 \%$ factor VII and normal levels of fibrinogen and other extrinsic clotting factors.

\section{5. vWF Assay Principle}

vWF is measured by VIDAS automated immunoassay system. A new automated quantitative enzyme linked immunosorbent assay (ELISA) for the detection of human von Willebrand factor, VIDAS vWF, has been developed for use on the VIDAS analyzer (BioMérieux). The two-step capture/tag test relies on two monoclonal antibodies [mAbs], the second one being labelled with alkaline phosphatase.

\section{Statistical Analysis}

Data were analyzed utilizing the STATA SOFTWARE. Continuous variables were expressed as means \pm standard deviation and nominal variables were recorded as frequencies. Student's unpaired $t$ test or Mann-Whitney test were used to compare continuous variables. The Chi2 test was used to identify differences between categorical variables. $P$ values less than 0.05 was considered to indicate statistical significance.

\section{Results}

From January 2012 to August 2013, three hundred liver cirrhotic patients underwent endoscopy. One hundred and sixty patients with esophageal variceal hemorrhage made up the study group and one hundred and forty patients with esophageal varices but no history of variceal hemorrhage comprised the negative control group. Two hundred and Forty (80\%) had Hepatitis C, Fifty Six (18\%) had hepatitis B, Six patients 2\% had both hepatitis B and C, $2 \%$ of all patients had HCC per biopsy factors for their liver disease. Male compromised $86 \%$ of the study population with a mean age of 42 years. The Physical examination are listed in Table 1, laboratory findings are listed in Table 2, there is significant decrease of hemoglobin level and platelet count in bleeding group when compared with non bleeding group. Also Table 2 shows significant increase in von Willebrand factor and significant decrease in FVII in bleeding group when compared with non bleeding group

No significant difference between both groups as regard splenomegaly, presence of ascites and presence of splenic or hepatic collaterals as shown in Table 3.

Endoscopic findings are listed in Table 4. High grade of varices, presence of red color sign [RC], number of columns of EV, presence of gastric varices and presence of portal gastropathy were significantly correlated with increased risk of bleeding from esophageal varices. RC sign is the most sensitive and specific sign for bleeding as shown in Table 5.

Table 5 shows the sensitivity, specificity and accuracy of various predictors of bleeding including the 
Table 1. Signs of clinical examination.

\begin{tabular}{rccc}
\hline Parameter & $\begin{array}{c}\text { Bleeding group } \\
\text { No. [Percent] }\end{array}$ & $\begin{array}{c}\text { Non bleeding group } \\
\text { No. [Percent] }\end{array}$ & $\begin{array}{c}\text { All patients value } \\
\text { No. [Percent] }\end{array}$ \\
\hline Encephalopathy: & $71[44.4 \%]$ & $116[82.9 \%]$ & $187[62.3 \%]$ \\
Grade 0 & $58[36.2 \%]$ & $20[14.3 \%]$ & $78[26 \%]$ \\
Grade1 & $21[13.1 \%]$ & $4[2.9 \%]$ & 0.001 \\
Grade 2 & $6[3.8 \%]$ & $0[0 \%]$ & $25[8.3 \%]$ \\
Grade 3 & $4[2.5 \%]$ & $0[0 \%]$ & $6[2 \%]$ \\
Grade 4 & & $4[1.3 \%]$ \\
\hline
\end{tabular}

Table 2. Laboratory data.

\begin{tabular}{|c|c|c|c|c|}
\hline Parameter & $\begin{array}{c}\text { Bleeding group } \\
\text { [Mean + SD] }\end{array}$ & $\begin{array}{c}\text { Non bleeding group } \\
\text { [Mean + SD] }\end{array}$ & $P$ value & $\begin{array}{l}\text { All patients } \\
\text { [Mean + SD] }\end{array}$ \\
\hline ALT & $48.10 \pm 17.28$ & $48.43 \pm 30.37$ & NS & $48.25 \pm 24.15$ \\
\hline Proth time. & $14.2 \pm 0.84$ & $14.0 \pm 0.79$ & NS & $14.1 \pm 0.92$ \\
\hline Total bilirubin & $2.01 \pm 1.41$ & $1.87 \pm 1.26$ & NS & $1.92 \pm 1.36$ \\
\hline Albumin & $2.83 \pm 0.57$ & $2.93 \pm 0.61$ & NS & $2.88 \pm 0.71$ \\
\hline Haemoglobin & $8.74 \pm 1.82$ & $11.68 \pm 1.59$ & 0.001 & $10.12 \pm 2.26$ \\
\hline Platelet count & $105.06 \pm 49.33$ & $170.41 \pm 65.39$ & 0.001 & $135.55 \pm 65.94$ \\
\hline Factor VII & $21.2 \pm 8.12$ & $34.4 \pm 6.08$ & 0.001 & $27.4 \pm 8.92$ \\
\hline vWF & $196.34 \pm 12.6$ & $179.17 \pm 11.2$ & 0.001 & $188.33 \pm 13.66$ \\
\hline
\end{tabular}

NS: non significant.

Table 3. Sonographic findings.

\begin{tabular}{|c|c|c|c|c|}
\hline Parameter & $\begin{array}{l}\text { Bleeding group } \\
\text { No. [Percent] }\end{array}$ & $\begin{array}{c}\text { Non bleeding group } \\
\text { No. [Percent] }\end{array}$ & $P$ value & $\begin{array}{l}\text { All patients } \\
\text { No. [Percent] }\end{array}$ \\
\hline Splenomegaly: & 129 [80.6\%] & 110 [78.5\%] & NS & 239 [79.6\%] \\
\hline PVD: & 85 [53.1\%] & 68 [48.6\%] & NS & 153 [51\%] \\
\hline \multicolumn{5}{|l|}{ Degree of ascites: } \\
\hline Minimal & 39 [24.4\%] & 37 [26.4\%] & \multirow{4}{*}{ NS } & 76 [25.3\%] \\
\hline Mild & 41 [25.6\%] & 32 [22.9\%] & & 73 [24.3\%] \\
\hline Moderate & 48 [30\%] & 42 [30] & & 90 [30\%] \\
\hline Marked & 17 [10.6\%] & 15 [11.4\%] & & 32 [10.6\%] \\
\hline Collatralls: & $48[30 \%]$ & 41 [29.2\%] & NS & 89 [29.7\%] \\
\hline
\end{tabular}

NS: non significant.

sensitivity and specificity of low FVII (<28.2\%) and high vWF (>187.1 IU/dl) to predict bleeding in patients having esophageal varices. The sensitivity of FVII and vWF were $75 \%$ and $82.5 \%$ respectively while the specificity were $85 \%$ and $65 \%$ respectively. We found no significant difference between patients with HCV infection and patients with HBV infections as regard the previous predictors of bleeding.

\section{Discussion}

Variceal hemorrhage is a major source of mortality of patients with portal hypertension [11], gastroesophageal varices are present in $50 \%-60 \%$ of cirrhotic patients. The natural history of liver cirrhosis shows that $30 \%$ of patients with liver cirrhosis will experience an episode of variceal hemorrhage within one year of diagnosis of varices [12]. Endoscopy proved to be a powerful tool for the determination of bleeding risks. Higher grade esophageal varices, red color sign, portal gastropathy and presence of fundal varices are other predictors of bleeding in esophageal varices. Our study has shown that large varices are more likely to bleed than small ones. Bleeding 
Table 4. Endoscopic finding.

\begin{tabular}{|c|c|c|c|c|}
\hline Parameter & $\begin{array}{l}\text { Bleeding group } \\
\text { No. [Percent] }\end{array}$ & $\begin{array}{l}\text { Non bleeding group } \\
\text { No. [Percent] }\end{array}$ & $P$ value & $\begin{array}{c}\text { All patients } \\
\text { No. [Percent] }\end{array}$ \\
\hline \multicolumn{5}{|l|}{ Grade of varices: } \\
\hline Grade 1 & $7[4.4 \%]$ & 112 [80\%] & 0.01 & 119 [39.7\%] \\
\hline Grade 2 & 29 [18.1\%] & 18 [12.8\%] & & 47 [15.7\%] \\
\hline Grade 3 & 98 [61.3\%] & 7 [5\%] & & 105 [35\%] \\
\hline Grade 4 & 29 [18.1\%] & $0[0 \%]$ & & 29 [9.7\%] \\
\hline \multicolumn{5}{|l|}{ Number pf varices: } \\
\hline One varix & 9 [5.6\%] & 62 [44.3\%] & 0.001 & $71[23.7 \%]$ \\
\hline Two varices & $10[6.3 \%]$ & 69 [49.3\%] & & 79 [26.3\%] \\
\hline Three varices & 56 [35\%] & $8[5.7 \%]$ & & 64 [21.3\%] \\
\hline Four varices & 85 [53.1\%] & $1[0.7 \%]$ & & 86 [28.7\%] \\
\hline Red sign: & 144 [90\%] & 9 [6.4\%] & 0.001 & 153 [51\%] \\
\hline Gastric varices: & 28 [17.5\%] & 13 [9.3\%] & 0.039 & 41 [13.7\%] \\
\hline Portal gastro: & 103 [64.4\%] & 12 [8.6\%] & 0.001 & 115 [38.3\%] \\
\hline
\end{tabular}

Table 5. Statistical parameters of various predictors of bleeding.

\begin{tabular}{cccc}
\hline Parameter & Accuracy\% & Sensitivity \% & Specificity\% \\
\hline $\begin{array}{c}\text { Low platelet count } \\
{\left[<13794 \times 10^{9} /\right]}\end{array}$ & 75.5 & 65.7 & 84.4 \\
Encephalopathy & 68.3 & 82.9 & 55.6 \\
$\geq$ 3 varices & 88.3 & 80 & 95.6 \\
Red color sign & 91.7 & 93.6 & 90 \\
Portal gastropathy association & 77 & 91.4 & 64.4 \\
High vWF [>187.1 IU/dl] & 73.8 & 82.5 & 65 \\
Low FVII $[<28.2 \%]$ & 80 & 75 & 85 \\
\hline
\end{tabular}

was present in $61.3 \%$ of our patients with grade 3 and in $18.1 \%$ with grade 4 varices. Wall tension is a factor of diameter and wall thickness, and it is not surprising that larger varices are more likely to rupture. Variceal size has been investigated by many researchers [13] [14]. All of them have documented the fact that larger varices bleed more often than smaller varices. The only exception to this is only one study found that 35\% of patients with small varices bled, while only $20 \%$ of patients with large varices also bled [15].

Another endoscopic finding of value in predicting variceal bleeding is the appearance of the vessel wall. The color of varices is thought to predict impending hemorrhage. Our study has shown that endoscopic finding of "red signs" is related to the variceal bleeding. The "red signs" were found in $90 \%$ of varices with bleeding. The red color signs are the result of microteleangioectasia of the varix. This agrees with many previous studies [16] [17]. In addition, the presence of concomitant gastric varices could be added as a further criterion for the prediction of bleeding from esophageal varices.

In agreement with previous, the presence of gastric varices in predicting bleeding from esophageal varices is noteworthy. Close anatomical connections have been demonstrated between the veins of the stomach and the distal esophagus. Furthermore, the presence of the varices in the gastric fundus indicates a particularly high venous blood pressure in that area thus offering an explanation for the increased bleeding risk [16]-[18].

In our study we found another criterion in predicting bleeding from esophageal varices is the presence of portal gastropathy on endoscopy. Prevalence of hypertensive gastropathy parallels the severity of portal hypertension and liver dysfunction. A high portal pressure [ $>12 \mathrm{mmHg}]$ can explain the snake skin appearance of gastric mucosa on endoscopy and positively correlates with the risk of bleeding this agree with previous studies [16]. We also found that increase the number of varices predicting bleeding from esophageal varices. 
In patients with liver cirrhosis elevated levels of von Willebrand factor antigen are found frequently but the clinical significance is unclear. VWF-Ag plays an important role in primary haemostasis and development of thrombotic vascular obliteration is discussed as a possible mechanism leading to portal hypertension [19]. Endothelial dysfunction is a major determinant of the increased hepatic vascular tone of cirrhotic livers. Von Willebrand factor [vWF], surrogate markers of endothelial dysfunction, is increased in patients with cirrhosis. So the vWF is increased in bleeding patients as increase of portal hypertension [20].

In our study we found that the increase of vWF correlates with the increased risk of bleeding form oesophageal varices as it significantly higher in patient with bleeding so it is significant predictor of bleeding.

Factor [F]V and FVII levels are sensitive indicators of hepatic protein synthesis often used to assess the severity of disease [4] [5]. FVII is the first clotting factor level to fall, because of its short half-life of 6 hours. FVII deficiency develops in $75 \%$ - $85 \%$ of patients, and levels range from $23 \%$ to $74 \%$ of normal in compensated cirrhosis [4] [6] [7]. FVII levels are significantly lower in decompensated cirrhosiss.

In our study significant decrease in FVII in bleeding group. Clinical trials are needed to better define the role of recombinant activated factor VII in the treatment of bleeding complications of liver disorder [21].

\section{Conclusion}

Our study concludes that vWF and FVII could be used as predictors for bleeding in patients having esophageal varices but further additional work should be done to study their roles in management.

\section{References}

[1] Paunescu, V., Grigorean, V. and Popescu, C. (2004) Risk Factors for Immediate Outcome of Gastrointestinal Bleeding in Patients with Cirrhosis. Chirurgia [Bucur], 99, 311-322.

[2] Alao, A., Sharara, M.D. and Don, C. and Rockey, M.D. (2001) Medical Progress Gastroesophageal Variceal Hemorrhage. New England Journal of Medicine, 345, 30.

[3] Goh, S.H., Tan, W.P. and Lee, S.W. (2005) Clinical Predictors of Bleeding Esophageal Varices in the ED. American Journal of Emergency Medicine, 23, 531-535.

[4] Green, G., Poller, L., Thomson, J.M., et al. (1976) Factor VII as a Marker of Hepatocellular Synthetic Function in Liver Disease. Journal of Clinical Pathology, 29, 971-975.

[5] Deitcher, S.R. (2002) Interpretation of the International Normalised Ratio in Patients with Liver Disease. Lancet, 359, 47-48.

[6] Hallen, A. and Nilsson, I.M. (1964) Coagulation Studies in Liver Disease. Thrombosis et Diathesis Haemorrhagica, 11, 51-63.

[7] Kupfer, H.G., Gee, W., Ewald, A.T., et al. (1964) Statistical Correlation of Liver Function Tests with Coagulation Factor Deficiencies in Laennec's Cirrhosis. Thrombosis et Diathesis Haemorrhagica, 10, 317-331.

[8] Kerr, R. (2003) New Insights into Haemostasis in Liver Failure. Blood Coagulation \& Fibrinolysis, 14, S43-S45.

[9] Beer, J.H., Clerici, N., Baillod, P., von Felten, A., Schlappritzi, E. and Buchi, L. (1995) Quantitative and Qualitative Analysis of Platelet GPIb and von Willebrand Factor in Liver Cirrhosis. Thrombosis and Haemostasis, 73, 601-609.

[10] Ferro, D., Quintarelli, C., Lattuada, A., Leo, R., Alessandroni, M., Mannucci, P.M., et al. (1996) High Plasma Levels of von Willebrand Factor as a Marker of Endothelial Perturbation in Cirrhosis: Relationship to Endotoxemia. Hepatology, 23, 1377-1383.

[11] Arguedas, M.R., Heudebert, G.R., Eloubeidi, M.A., Abrams, G. and Fallon, M.B. (2002) Cost-Effectiveness of Screening, Surveillance, and Primary Prophylaxis Strategies for Esophageal Varices. American Journal of Gastroenterology, 97, 2441-2452.

[12] Paunescu, V., Grigorean, V. and Popescu, C. (2004) Risk Factors for Immediate Outcome of Gastrointestinal Bleeding in Patients with Cirrhosis. Chirurgia [Bucur], 99, 311-322.

[13] De Franchis, R. and Primignani, M. (1992) Why Do Varices Bleed? Gastroenterology Clinics of North America, 21, 85-101.

[14] Burroughs, A.K. and McCormick, P.A. (1992) Preventin of Variceal Rebleeding. Gastroenterology Clinics of North America, 21, 119-147.

[15] Koch, H., Henning, H., Grimm, H. and Soehendra, N. (1986) Prophylactic Sclerosing of Oesophageal Varices-Results of a Prospective Controlled Study. Endoscopy, 18, 40-43.

[16] Limquiaco, J., Eulenia, R.N., Maria, L.O., Venancio, I.G., Ernesto, O.D., Virgilio, P.B., Felix, M.Z., Melflor, A.A., Pe- 
ter, P.S., Labio, E. and Antonio, C.C. (2006) Clinical Predictors of Bleeding from Esophageal Varices. A Retrospective Study Phil Journal of Gastroenterology, 2, 103-111.

[17] Benedeto-Stojanov, D., et al. (2006) Predictive Factors of Bleeding from Esophageal Varicies in Patient with Liver Cirrhosis and Portal Hypertension. Medicine and Biology, 13, 164-167.

[18] Watanabe, K. and Kimujra, K. (1988) Portal Hemodynamics in Patients with Gastric Varices. Gastroenterology, 95, 434-440.

[19] Ferlitsch, M., Reiberger, T., Hoke, M., Salzl, P., Schwengerer, B., Ulbrich, G., Payer, B.A., Trauner, M., Peck-Radosavljevic, M. and Ferlitsch (2012) A von Willebrand Factor as New Noninvasive Predictor of Portal Hypertension, Decompensation and Mortality in Patients with Liver Cirrhosis. Hepatology, 56, 1439-1447.

[20] Iwakiri, Y. and Groszmann, R.J. (2007) Vascular Endothelial Dysfunction in Cirrhosis. Journal of Hepatology, 46, 927-933.

[21] Franchini, M., Montagnana, M., Targher, G., Zaffanello, M. and Lippi, G. (2008) The Use of Recombinant Factor VIIa in Liver Diseases. Blood Coagulation \& Fibrinolysis, 19, 341-348. 